\title{
Who are the cancer survivors? A nationwide study in Denmark, 1943-2010
}

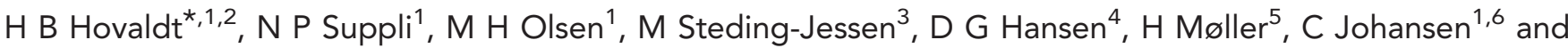 \\ S O Dalton ${ }^{1}$
}

${ }^{1}$ Danish Cancer Society Research Center, Unit of Survivorship, Strandboulevarden 49, DK-2100 Copenhagen Ø, Denmark; ${ }^{2}$ Department of Psychology, University of Copenhagen, Øster Farimagsgade 2a, DK-1353 Copenhagen K, Denmark; ${ }^{3}$ Danish Cancer Society, Documentation and Quality, Strandboulevarden 49, DK-2100 Copenhagen Ø, Denmark; ${ }^{4}$ National Research Center for Cancer Rehabilitation, Research Unit of General Practice, University of Southern Denmark, J.B. Winsløws Vej 9, Entrance B, 1st Floor, DK-5000 Odense C, Denmark; ${ }^{5}$ King's College London, Section of Cancer Epidemiology and Population Health, Bermondsey Wing, 3rd Floor, Guy's Hospital, Great Maze Pond, London SE1 9RT, UK and 'Department of Oncology, Rigshospitalet, Blegdamsvej 9, DK-2100 Copenhagen $\varnothing$, Denmark

Background: No nationwide studies on social position and prevalence of comorbidity among cancer survivors exist.

Methods: We performed a nationwide prevalence study defining persons diagnosed with cancer $1943-2010$ and alive on the census date 1 January 2011 as cancer survivors. Comorbidity was compared by social position with the non-cancer population.

Results: Cancer survivors composed $4 \%$ of the Danish population. Somatic comorbidity was more likely among survivors (OR 1.59, 95\% Cl 1.57-1.60) and associated with higher age, male sex, short education, and living alone among survivors.

Conclusions: Among cancer survivors, comorbidity is common and highly associated with social position.

The number of cancer survivors is increasing in many countries (Engholm et al, 2010; Maddams et al, 2012; de Moor et al, 2013), mainly due to ageing populations and decreasing cancer mortality as a result of better diagnostics and treatment (Moller et al, 2002; Jemal et al, 2004; Australian Institute of Health and Welfare, Cancer Australia \& Australasian Association of Cancer Registries, 2008; Rowland and Bellizzi, 2008; Parry et al, 2011). To our knowledge, no nationwide studies of social position and the prevalence of comorbidity have been performed among cancer survivors. Defining cancer survivors from date of diagnosis and throughout their lives (National Cancer Institute, 2014), we thoroughly characterised the national population of such survivors, compared the total burden of severe somatic comorbidity in cancer survivors and the non-cancer population, and described potential differences by social position among the cancer survivors.

\section{MATERIAL AND METHODS}

Study design and population. We performed a cross-sectional study of all people living in Denmark on 1 January 2011, who were identified in the civil registration system, comprising 5560628 people (Pedersen, 2011). Since 1943, all cases of cancer have been registered in the Danish Cancer Registry (Gjerstorff, 2011). We identified all persons diagnosed with cancer (excluding benign tumours, in situ cancers and non-melanoma skin cancers) in 19432010 and classified them according to their first (index) cancer.

Somatic comorbidity measured by the Charlson Comorbidity Index (CCI) was calculated based on discharge information from 1978 (inpatient) and 1995 (outpatient) to census date from the National Patient Registry (Lynge et al, 2011) and information on all subsequent primary malignancies after the index cancer from the Danish Cancer Registry (Charlson et al, 1987; Dalton et al, 2008a). From the Danish Psychiatric Case Register (Mors et al, 2011), we defined severe psychiatric comorbidity as hospital contacts from 1969 (inpatient) or 1995 (outpatient) to the census date for schizophrenia and psychosis and affective disorders (Dalton et al, 2008a).

Education and cohabitation status was used as indicators for social position. Information was derived from the Integrated Database for Labour Market Research in Statistics Denmark (Thygesen, 1995) and the Danish Civil Registration System

*Correspondence: HB Hovaldt; E-mail: habiho@cancer.dk or hanna.hovaldt@psy.ku.dk

Received 29 August 2014; revised 7 January 2015; accepted 27 January 2015; published online 26 February 2015

(c) 2015 Cancer Research UK. All rights reserved 0007-0920/15 
containing information on all Danish residents. Social position analyses were restricted to 30-90-year olds, as information on education was not available for people born before 1920, and many Danes finish their education in the late twenties. Highest attained educational level was categorised as short (mandatory education, 7-9 years), medium, (high school or vocational education, 8-12 and 10-12 years of education for people born before and after 1958, respectively), and long education ( $>12$ years, i.e., higher education). Cohabitation status was defined as cohabiting (married or cohabiting with partner), widow/widower, divorced, and single (not cohabiting and never married).

Statistical analysis. The prevalence of cancer survivors was calculated from the number of people with a cancer diagnosis in the population on 1 January 2011. To analyse the risk for a CCI score $\geqslant 1$ depending on being a cancer survivor, multivariate logistic regression analyses were performed with adjustment for sex, age, schizophrenia or psychosis, and affective disorders. The association between education and cohabitation status and somatic comorbidity was examined in 30-90-year olds by multivariate logistic regression analyses stratified by cancer survivor or non-cancer population and time since diagnosis and adjusted for education, cohabitation status, sex, age, schizophrenia or psychosis, affective disorder, and cancer diagnosis (only in cancer survivors). Age was modelled as a secondorder polynomial in all regression analyses.

\section{RESULTS}

On 1 January 2011, 227704 cancer survivors were living in Denmark, corresponding to $4 \%$ of the total population. The median age of the cancer survivors was 67 years; $13 \%$ of $60-89$-year olds and $18 \%$ of $\geqslant 90$-year olds were cancer survivors (Table 1). Nearly $8 \%$ of cancer survivors had had more than one cancer (Table 2).

Median time since diagnosis was 6 years. Approximately onethird of people with cancers of the lung, esophagus, stomach, and pancreas had survived $<1$ year after diagnosis. One-third of survivors of female genital cancers had received their diagnosis $\geqslant 20$ years before the census date, but only $4 \%$ of lung cancer survivors (Supplementary Information S1).

A CCI score $\geqslant 1$ was found for $40 \%$ of the cancer survivors and for $16 \%$ of the non-cancer population, whereas prevalence of affective disorders and schizophrenia or psychosis was similar

Table 1. Basic characteristics of 5560628 people living in Denmark on 1 January 2011

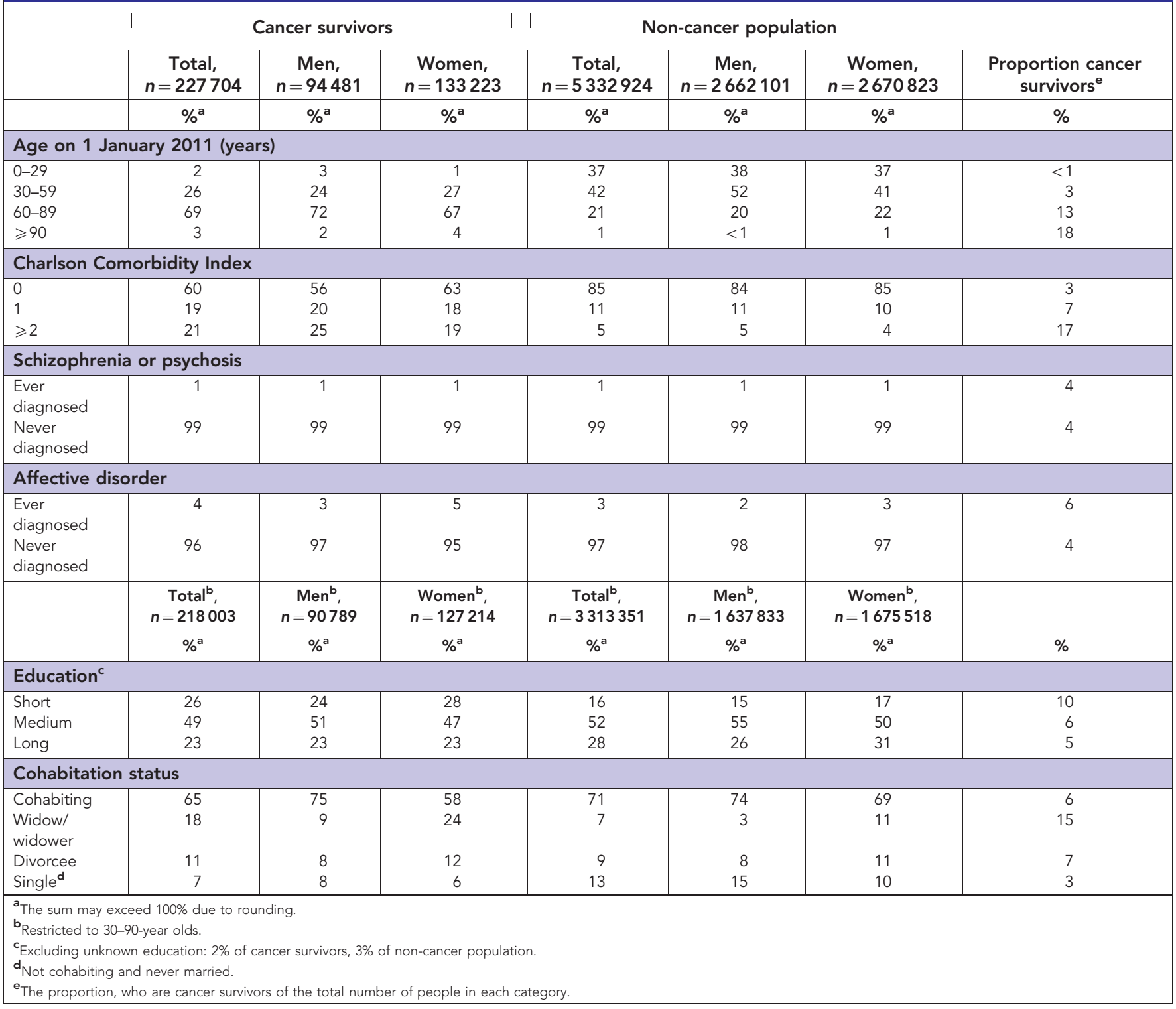


(Table 1). The proportion of survivors with a CCI score $\geqslant 1$ ranged from $58 \%$ for lung cancer survivors to $29 \%$ for survivors of malignant melanoma. In comparison with the non-cancer population, the OR of all cancer survivors for having a CCI score $\geqslant 1$ was 1.59 (95\% CI 1.57-1.60) after adjustment for sex and age. Adjustments for psychiatric comorbidity did not change the

Table 2. Cancer-specific characteristics of 227704 cancer survivors living in Denmark on 1 January 2011

\begin{tabular}{|c|c|c|c|}
\hline & $\begin{array}{c}\text { Total, } \\
\mathbf{2}=\mathbf{2 7} 704, \\
\%^{\mathrm{a}}\end{array}$ & $\begin{array}{c}\begin{array}{c}\text { Men, } \\
n=94481 \\
\%^{\mathrm{a}}\end{array}\end{array}$ & $\begin{array}{c}\text { Women } \\
n=133223 \\
\%^{a}\end{array}$ \\
\hline \multicolumn{4}{|l|}{ Index cancer type ${ }^{b}$} \\
\hline Mouth, pharynx and larynx & 2 & 4 & 1 \\
\hline $\begin{array}{l}\text { Esophagus, stomach and } \\
\text { pancreas }\end{array}$ & 1 & 2 & 1 \\
\hline Colon and rectum & 11 & 13 & 10 \\
\hline Lung & 3 & 3 & 3 \\
\hline Breast & 23 & $<1$ & 39 \\
\hline Female genitalia & 10 & - & 17 \\
\hline Male genitalia & 13 & 32 & - \\
\hline Kidney and bladder & 8 & 14 & 4 \\
\hline Malignant melanoma & 8 & 8 & 9 \\
\hline Central nervous system & 6 & 6 & 6 \\
\hline Leukemias, NHL and HL & 7 & 9 & 5 \\
\hline Other cancers & 7 & 8 & 6 \\
\hline \multicolumn{4}{|c|}{ Age at diagnosis of index cancer (years) } \\
\hline $0-29$ & 6 & 8 & 6 \\
\hline $30-59$ & 46 & 35 & 51 \\
\hline $60-89$ & 48 & 56 & 42 \\
\hline$\geqslant 90$ & $<1$ & $<1$ & 1 \\
\hline \multicolumn{4}{|c|}{ Time since diagnosis of index cancer (years) } \\
\hline$<1$ & 11 & 13 & 9 \\
\hline $1-4$ & 31 & 36 & 27 \\
\hline $5-9$ & 22 & 22 & 22 \\
\hline $10-19$ & 22 & 18 & 25 \\
\hline$\geqslant 20$ & 15 & 11 & 18 \\
\hline \multicolumn{4}{|c|}{ No. of primary cancers after index cancerb } \\
\hline 0 & 93 & 93 & 93 \\
\hline 1 & 7 & 7 & 7 \\
\hline$\geqslant 2$ & 1 & 1 & 1 \\
\hline \multicolumn{4}{|c|}{$\begin{array}{l}\text { Abbreviations: } \mathrm{HL}=\text { Hodgkin lymphoma; } \mathrm{NHL}=\text { non-Hodgkin lymphoma. } \\
{ }^{\mathrm{a}} \text { The sum may exceed } 100 \% \text { due to rounding. }\end{array}$} \\
\hline bxcluding benign tumours, car & er in situ, and non-1 & elanoma skin car & \\
\hline
\end{tabular}

estimate. Male sex and older age were associated with significantly increased odds for a CCI score $\geqslant 1$ (data not shown).

Level of education and cohabitation status varied by cancer type, but cancer survivors with short education had the highest proportion of somatic and psychiatric comorbidity in all the age groups (Supplementary Information S2). Compared with survivors with higher education, those with short education had 57\% higher odds for having a CCI score $\geqslant 1$ (95\% CI 1.53-1.62), and survivors with medium education had 33\% higher odds (95\% CI 1.29-1.36). Living alone was also significantly associated with higher odds for a CCI score $\geqslant 1$ in comparison with cohabiting; divorced people had the highest odds (OR 1.45, 95\% CI 1.41-1.50) (Table 3). The social gradient in somatic comorbidity was slightly smaller among cancer survivors than the non-cancer population and tended to be smaller with time after diagnosis (Table 3).

\section{DISCUSSION}

Cancer survivors have substantially higher odds for comorbid diseases in addition to their cancer than the cancer-free population. Short education and living alone were consistently associated with higher odds for comorbid diseases.

Our results confirm the prevalence of cancer type, age, sex and time since diagnosis found previously (Maddams et al, 2009; Siegel et al, 2012; Underwood et al, 2012; de Moor et al, 2013; Gatta et al, 2013; Jarlbaek et al, 2014); however, this is the first study to report results from a nationwide population with combined registry-based information on both cancer, demography, comorbidity, and social position.

Results from the National Health Interview Survey in the United States $(n=7292)$ indicated a higher prevalence of somatic comorbidity among both cancer survivors (57.7\%) and matched controls $(45.2 \%)$ than in our study; however, the survey data on comorbidity were self-reported in relation to functional limitations (Yabroff et al, 2004). We ensured consistent reporting of severe comorbid diseases leading to hospital contacts and found that cancer survivors had significantly greater odds for somatic comorbidity than the non-cancer population, which might be due to preexisting morbidity, late effects of cancer and cancer treatment, shared risk factors such as lifestyle, environmental exposure, and genetics, or joint effects of these (Aziz, 2007). Furthermore, the non-cancer illness of cancer survivors may not be

Table 3. Multivariate logistic regression analyses of the odds ratio (OR) with $95 \%$ confidence intervals ( $95 \%$ Cls) between somatic comorbidity $(\mathrm{CCl} \geqslant 1)$, education, and cohabitation status among cancer survivors $(n=218003)$ and the non-cancer population $(n=3313351)$ aged $30-90$ years, living in Denmark on 1 January 2011, adjusted for sex and age

\begin{tabular}{|c|c|c|c|c|c|c|c|c|c|c|c|c|c|c|}
\hline & \multicolumn{2}{|c|}{$\begin{array}{l}\text { Non-cancer } \\
\text { population, } \\
n=3313351\end{array}$} & \multicolumn{2}{|c|}{$\begin{array}{c}\text { Cancer } \\
\text { survivors, } \\
n=218003\end{array}$} & \multicolumn{2}{|c|}{$\begin{array}{c}\text { Cancer } \\
\text { survivors } \\
<1 \text { year } \\
\text { after } \\
\text { diagnosis, } \\
\mathbf{n}=\mathbf{2 3} 958\end{array}$} & \multicolumn{2}{|c|}{$\begin{array}{c}\text { Cancer } \\
\text { survivors } \\
1-4 \text { years } \\
\text { after } \\
\text { diagnosis, } \\
n=67262\end{array}$} & \multicolumn{2}{|c|}{$\begin{array}{c}\text { Cancer } \\
\text { survivors } \\
5-9 \text { years } \\
\text { after } \\
\text { diagnosis, } \\
n=47577\end{array}$} & \multicolumn{2}{|c|}{\begin{tabular}{|c|} 
Cancer \\
survivors \\
10-19 years \\
after \\
diagnosis, \\
$n=47539$
\end{tabular}} & \multicolumn{2}{|c|}{$\begin{array}{c}\text { Cancer } \\
\text { survivors } \\
\geqslant 20 \text { years } \\
\text { after } \\
\text { diagnosis, } \\
n=31667\end{array}$} \\
\hline & OR & $95 \% \mathrm{Cl}$ & OR & $95 \% \mathrm{Cl}$ & OR & $95 \% \mathrm{Cl}$ & OR & $95 \% \mathrm{Cl}$ & OR & $95 \% \mathrm{Cl}$ & OR & $95 \% \mathrm{Cl}$ & OR & $95 \% \mathrm{Cl}$ \\
\hline \multicolumn{15}{|l|}{ Education } \\
\hline Short & 1.71 & $1.70-1.73$ & 1.57 & $1.53-1.62$ & 1.74 & $1.60-1.89$ & 1.64 & $1.56-1.72$ & 1.63 & $1.53-1.72$ & 1.49 & $1.41-1.58$ & 1.40 & $1.31-1.51$ \\
\hline Medium & 1.34 & $1.33-1.35$ & 1.33 & $1.29-1.36$ & 1.39 & $1.29-1.49$ & 1.35 & $1.29-1.40$ & 1.34 & $1.27-1.41$ & 1.31 & $1.25-1.38$ & 1.24 & $1.17-1.32$ \\
\hline Long & 1.00 & Reference & 1.00 & Reference & 1.00 & Reference & 1.00 & Reference & 1.00 & Reference & 1.00 & Reference & 1.00 & Reference \\
\hline \multicolumn{15}{|c|}{ Cohabitation status } \\
\hline Cohabiting & 1.00 & Reference & 1.00 & Reference & 1.00 & Reference & 1.00 & Reference & 1.00 & Reference & 1.00 & Reference & 1.00 & Reference \\
\hline Widow/widower & 1.11 & $1.10-1.13$ & 1.14 & $1.11-1.17$ & 1.17 & $1.07-1.27$ & 1.18 & $1.12-1.24$ & 1.12 & $1.06-1.18$ & 1.11 & $1.05-1.18$ & 1.11 & $1.04-1.18$ \\
\hline Divorced & 1.48 & $1.47-1.50$ & 1.45 & $1.41-1.50$ & 1.52 & $1.40-1.66$ & 1.46 & $1.38-1.54$ & 1.49 & $1.40-1.59$ & 1.43 & $1.35-1.53$ & 1.33 & $1.24-1.44$ \\
\hline Single ${ }^{a}$ & 1.24 & $1.23-1.26$ & 1.25 & $1.21-1.30$ & 1.23 & $1.10-1.38$ & 1.29 & $1.20-1.38$ & 1.26 & $1.16-1.37$ & 1.19 & $1.10-1.29$ & 1.21 & $1.10-1.33$ \\
\hline
\end{tabular}


managed optimally (Earle and Neville, 2004) contributing to the risk of hospitalisation for comorbidity.

Previous studies have shown that low social position is associated with higher cancer incidence for selected cancers and poorer survival after most cancers (Dalton et al, 2008b) and a higher risk for comorbid disease at the time of cancer diagnosis (Louwman et al, 2010). We show that the social gradient continues into life after cancer, a gradient that could not be explained by case-mix due to cancer type alone. We found that the social differences were smaller among those who had survived longer, which might be due to the social gradient in cancer survival (Dalton et al, 2008b), and because comorbidity is a strong predictor for early mortality from cancer (Yancik et al, 2001; Piccirillo et al, 2004).

The primary aim of this study was to characterise comorbidity and social position in a nationwide population of cancer survivors; however, information on individual lifestyle and behaviour could have provided further insight, as these are risk factors for both cancer and comorbid diseases. As the aim was to investigate the total burden of severe comorbidity, we included all comorbid diseases occurring before and after the index cancer. As secondary primary malignancies were included only for cancer survivors, comorbidity might be a late effect of cancer treatment and/or due to shared risk factors. Most comorbid conditions in people with recent cancers date from before the index cancer, while people with earlier cancers have comorbid conditions from after the index cancer. Finally, time since diagnosis was truncated, as cancer registration started in 1943; thus, people with cancers diagnosed before 1943, and alive on 1 January 2011, were not defined as cancer survivors but we expect the underestimation of prevalence to be small.

This study, based on nationwide data, provides new insight into the total burden of severe comorbidity in the growing group of cancer survivors. Use of national registers prevents bias and provides consistent, complete, and valid individual-level information on social factors and morbidity, and the long tradition of systematic registration of cancer in Denmark ensures almost complete registration of cases.

\section{CONCLUSION AND IMPLICATIONS}

The population of Danish cancer survivors is large and some have survived for decades after their initial diagnosis. Beyond being impaired by the cancer treatment, cancer survivors are more affected by other chronic disorders than their non-cancer fellows, especially survivors with low social position. Further investigation of the causes of social differences in comorbidity are important to ensure equal access and optimal care and rehabilitation of both cancer and comorbid diseases for all cancer survivors.

\section{ACKNOWLEDGEMENTS}

This work was supported by the Danish Cancer Society.

\section{CONFLICT OF INTEREST}

The authors declare no conflict of interest.

\section{REFERENCES}

Australian Institute of Health and Welfare, Cancer Australia \& Australasian Association of Cancer Registries (2008) Cancer Survival and Prevalence in Australia: Cancer diagnosed from 1982 to 2004. Australian Institute of
Health and Welfare: Canberra, Australia, Cancer Series no. 42. Cat. No. CAN 38.

Aziz NM (2007) Cancer survivorship research: state of knowledge, challenges and opportunities. Acta Oncol 46: 417-432.

Charlson ME, Pompei P, Ales KL, MacKenzie CR (1987) A new method of classifying prognostic comorbidity in longitudinal studies: development and validation. J Chronic Dis 40: 373-383.

Dalton SO, Steding-Jessen M, Gislum M, Frederiksen K, Engholm G, Schuz J (2008a) Social inequality in incidence of and survival from cancer in a population-based study in Denmark, 1994-2003: Background, aims, material and methods. Eur J Cancer 44: 1938-1949.

Dalton SO, Schuz J, Engholm G, Johansen C, Kjaer SK, Steding-Jessen M, Storm HH, Olsen JH (2008b) Social inequality in incidence of and survival from cancer in a population-based study in Denmark, 1994-2003: summary of findings. Eur J Cancer 44: 2074-2085.

de Moor JS, Mariotto AB, Parry C, Alfano CM, Padgett L, Kent EE, Forsythe L, Scoppa S, Hachey M, Rowland JH (2013) Cancer survivors in the United States: prevalence across the survivorship trajectory and implications for care. Cancer Epidemiol Biomarkers Prev 22: 561-570.

Earle CC, Neville BA (2004) Under use of necessary care among cancer survivors. Cancer 101: 1712-1719.

Engholm G, Gislum M, Bray F, Hakulinen T (2010) Trends in survival of patients diagnosed with cancer in the Nordic countries 1964-2003 followed up to the end of 2006. Material and methods. Acta oncol 49: 545-560.

Gatta G, Mallone S, van der Zwan JM, Trama A, Siesling S, Capocaccia R (2013) Cancer prevalence estimates in Europe at the beginning of 2000. Ann Oncol 24: 1660-1666.

Gjerstorff ML (2011) The Danish Cancer Registry. Scand J Public Health 39: $42-45$.

Jarlbaek L, Christensen L, Bruera E, Hansen DG (2014) The epidemiology of long- and short-term cancer survivors. A population-based cohort study exploring denominators for rehabilitation and palliative care programs. Acta oncol 53: 493-501.

Jemal A, Clegg LX, Ward E, Ries LA, Wu X, Jamison PM, Wingo PA, Howe HL, Anderson RN, Edwards BK (2004) Annual report to the nation on the status of cancer, 1975-2001, with a special feature regarding survival. Cancer 101: 3-27.

Louwman WJ, Aarts MJ, Houterman S, van Lenthe FJ, Coebergh JWW, Janssen-Heijnen MLG (2010) A 50\% higher prevalence of life-shortening chronic conditions among cancer patients with low socioeconomic status. Br J Cancer 103: 1742-1748.

Lynge E, Sandegaard JL, Rebolj M (2011) The Danish National Patient Registry. Scand J Public Health 39: 30-33.

Maddams J, Brewster D, Gavin A, Steward J, Elliott J, Utley M, Møller H (2009) Cancer prevalence in the United Kingdom: estimates for 2008. Br J Cancer 101: 541-547.

Maddams J, Utley M, Møller H (2012) Projections of cancer prevalence in the United Kingdom, 2010-2040. Br J Cancer 107: 1195-1202.

Moller B, Fekjaer H, Hakulinen T, Tryggvadottir L, Storm HH, Talback M, Haldorsen T (2002) Prediction of cancer incidence in the Nordic countries up to the year 2010. Eur J Cancer Prev 11: S1-96.

Mors O, Perto GP, Mortensen PB (2011) The Danish Psychiatric Central Research Register. Scand J Public Health 39: 54-57.

National Cancer Institute (2014) Definitions: Survivorship definitions. Retrieved 8 July 2014, from http://cancercontrol.cancer.gov/ocs/statistics/ definitions.htmls.

Parry C, Kent EE, Mariotto AB, Alfano CM, Rowland JH (2011) Cancer survivors: a booming population. Cancer Epidemiol Biomarkers Prev 20: 1996-2005.

Pedersen CB (2011) The Danish Civil Registration System. Scand J Public Health 39: 22-25.

Piccirillo JF, Tierney RM, Costas I, Grove L, Spitznagel Jr EL (2004) Prognostic importance of comorbidity in a hospital-based cancer registry. JAMA 291: 2441-2447.

Rowland JH, Bellizzi KM (2008) Cancer survivors and survivorship research: a reflection on today's successes and tomorrow's challenges. Hematol Oncol Clin North Am 22: 181-200.

Siegel R, DeSantis C, Virgo K, Stein K, Mariotto A, Smith T, Cooper D, Gansler T, Lerro C, Fedewa S, Lin C, Leach C, Cannady RS, Cho H, Scoppa S, Hachey M, Kirch R, Jemal A, Ward E (2012) Cancer treatment and survivorship statistics, 2012. CA Cancer J Clin 62: 220-241.

Thygesen L (1995) The register-based system of demographic and social statistics in Denmark. Stat J UN Econ Comm Eur 12: 49-55. 
Underwood JM, Townsend JS, Stewart SL, Buchannan N, Ekwueme DU, Hawkins NA, Li J, Peaker B, Pollack LA, Richards TB, Rim SH, Rohan EA, Sabatino SA, Smith JL, Tai E, Townsend G, White A, Fairley TL (2012) Surveillance of demographic characteristics and health behaviors among adult cancer survivors-behavioral risk factor surveillance system, United States, 2009. MMWR Surveill Summ 61: $1-23$.

Yabroff KR, Lawrence WF, Clauser S, Davis WW, Brown ML (2004) Burden of illness in cancer survivors: findings from a population-based national sample. J Natl Cancer Inst 96: 1322-1330.
Yancik R, Wesley MN, Ries LAG, Havlik RJ, Edwards BK, Yates JW (2001) Effect of age and comorbidity in postmenopausal breast cancer patients aged 55 years or older. JAMA 285: 885-892.

This work is published under the standard license to publish agreement. After 12 months the work will become freely available and the license terms will switch to a Creative Commons AttributionNonCommercial-Share Alike 4.0 Unported License.

Supplementary Information accompanies this paper on British Journal of Cancer website (http://www.nature.com/bjc) 